\title{
Applying Online Collaborative Writing to Enhance SIU Sophomore English Majors' Writing Skills
} A Case Study at the Saigon International University

\author{
Nguyen Thi Kim Chung ${ }^{1}$, Tong Trieu Anh Thu ${ }^{1 . *}$, \\ Le Thi Ngoc Tuyen ${ }^{1}$, Nguyen Long Tien ${ }^{1}$ \\ ${ }^{1}$ Department of Foreign Languages, The Saigon International University, Ho Chi Minh City, Vietnam \\ *Corresponding author. E-mail: tongtrieuanhthu@siu.edu.vn
}

\begin{abstract}
Online learning that makes learning more engaging and stimulating has long been a part of $21^{\text {st }}$-century education. This case study explores how online collaborative writing helps to improve EFL students' writing skills and how students perceive the use of this teaching method. The Saigon International University participants included 19 English-majored students who practiced writing collaboratively with Google Documents throughout a 15-week Writing course. They were first instructed to individually brainstorm vocabulary and structures needed for an essay before working together in groups to create an essay outline. The lecturer played the role of a facilitator to assign tasks for each group, supervise, and provide instant feedback during the process of essay writing. Data were collected through a pre-test, a post-test, and questionnaires, and then were analyzed using the mixed methods approach. The results indicated that most participants made a significant improvement in their writing abilities as well as tended to have a positive attitude towards this innovative method. Due to the lack of past literature exploring the impacts of such an online teaching approach on enhancing writing skills, this case study is of vital importance as it provides an in-depth understanding of the educational technology for improving learning performance.
\end{abstract}

Keywords: online collaborative learning, writing skills, perceptions.

\section{INTRODUCTION}

\subsection{Rationale}

The age of rapid technological advances has provided a variety of convenient appliances that have facilitated human lives in a lot of ways. Particularly, the development of technology has offered various tools to assist the process of teaching and learning. Thus, teachers are able to make their lessons more stimulating to engage students in the process of learning and acquiring knowledge.

In Vietnam, especially in big cities, many classrooms have been equipped with computers, projectors, and audio systems to assist the process of teaching and learning English. In addition, most college students now have their own mobile phones and laptops; however, those modern appliances have mainly been used for entertainment purposes, which might distract them from their learning. Therefore, finding ways to enable students to utilize their laptops and mobile phones for learning purposes has long been a concern among teachers. This issue is also challenging for those who are in charge of teaching English writing since it is difficult to make the writing lessons intriguing and get students involved. Nowadays, with the assistance of Google Documents - an application developed by Google, teachers worldwide have been integrating it into their lessons to create a positive classroom atmosphere where students can work with their friends collaboratively to practice English writing. Accordingly, to deal with the current issues, online collaborative writing has been implemented to teach writing skills to some of the English-majored students at The Saigon International University (SIU), and the impacts of such a teaching method on students' writing abilities as well as their beliefs will be explored in this case study.

\subsection{Research goals}

This research was carried out to discover how online collaborative writing influenced the students' writing skills and other related skills. Furthermore, this study 
also aimed to explore the students' perceptions of this teaching method and what can be done to better the teaching process so that it will be more beneficial to the students.

\subsection{Significance of the research}

This study is expected to bring both theoretical and pedagogical benefits. Although it is generally accepted that collaborative writing has specific influences on the enhancement of students' writing skills, its effects in the specific context of the Saigon International University still remain unknown. This research's findings are supposed to help lecturers broaden their knowledge about online collaborative writing and the procedures of applying it in the teaching process. Also, this study's findings might encourage other lecturers in the university to apply online collaborative writing to their own teaching practice, which is expected to be more beneficial to the students. Finally, this research is likely to provide other researchers with valuable data for their studies on the future's related topics.

\subsection{Research questions}

This study aimed to investigate the effects of collaborative writing at The Saigon International University. In particular, this study examined the two following research questions:

a. What are the effects of online collaborative writing on students' writing abilities in English classes at the Saigon International University?

b. What are the students' perceptions of the application of online collaborative writing in writing classes?

\subsection{Limitations}

The first limitation of this study is likely to be the sample. The study participants were 19 students (in an English-majored class) at The Saigon International University. This population was only a specific group of students, and the sample size was quite small. Therefore, this study seems to lack generalization. Another drawback is the short period of time in which the study was conducted - one semester. After such a limited time, it was hard to evaluate students' improvement thoroughly as well as to investigate whether the effects of this method are long-lasting.

\section{LITERATURE REVIEW}

\subsection{Theory framework}

In order to select an appropriate and efficient teaching approach to foster students' learning, it is vital to gain deep insights into the features of learning. According to the constructivist learning theory, students themselves construct their understanding of the world based on their own experience and prior knowledge; in addition, social interaction plays an imperative role in enhancing learning (Good \& Brophy cited in Cooperstein \& Kocevar-Weidinger, 2004) [8].
Additionally, while Bruner (1966) [5] states that it is crucial to teach students to think critically and actively participate in the process of learning, Vygotsky (1978) [21] underlines the role of social interaction among students as well as between a student and a teacher in enhancing students' learning. It goes without saying that it is essential for students to work on their own as well as to collaborate with their friends in the process of acquiring knowledge. As a result, cooperative writing seems to be a suitable teaching method to foster students' learning because it seems to allow students to work collaboratively and work collaboratively with their friends.

\subsection{Definition of collaborative learning and writing}

The term collaborative learning is used by Felder and Brent (2007) [10] to refer to the learning process in which learners collaboratively work with each other to deal with a project or an assignment. Each student is individually responsible for the completion of the assigned project or assignment. A further definition of collaborative learning is given by Abdel Hakim (2011) [1], who describes it as some processes of learning in which learners are assigned to work in teams to handle specific tasks. In order to complete the assignments, learners are required to communicate with each other and share ideas. Collaborative writing is defined by Storch (2012) [19] as a writing activity in which writers work in pairs or in groups to produce a text. This activity consists of not only the process but also the product. In the process of writing, all the members are required to actively work together to generate ideas, decide on grammatical structures, and proofread the final draft. This collaborative writing process will result in the final product.

\subsection{Definition of "case study"}

According to Mitchell (1983) [15], a case study is described as a process of examining a circumstance or a series of circumstances that are related to each other in detail to discover some general principles of theories in operation. Besides, in the writing guide of Colorado State University (1993-2020), a case study is defined as a qualitative study that can be used to examine some participants individually, a small number of people, or a whole group. As of the above-mentioned definitions, a case study is undoubtedly one of the most effective methods for researchers to realize both theoretical and practical aims. Case studies are designed as real-life situations that can be analyzed, understood, and dissected based on theoretical knowledge.

\subsection{The advantages and disadvantages of online collaborative learning and writing}

According to Chiong and Jovanovic (2012) [6], one of the advantages of online collaborative learning is that it enhances positive comparison and competition. The participants in their research revealed that the online 
learning environment provided them with opportunities to compare their work's speed and progress to those of the other members in their group. In addition, working with their friends on an assigned task was believed to prepare those students for the competitive workplace in the future. That the students felt competitive seemed to result from the fact that they had to submit their own work although they worked together in a team.

In addition to the advance of collaborative learning itself, collaboration gives further outcomes when carried out in online learning settings. Since the study materials, discussion questions, and tests are stored on an online platform, students can easily access these contents at any time and anywhere. All the participants can perform learning activities right at the same time, even giving ideas in a discussion, and they will be then recorded in case students need to use them later.

Next, online collaborative learning can create more opportunities for students to interact with other members and teachers. The introverted students can find it easier to participate in discussions during classes, rather than traditional collaboration methods, since online collaboration is both open and secret. Students learn to present their opinions, listen to other people's ideas critically; then, they can easily integrate into the group community, giving confidence and interest in learning and living. In the study conducted by Zhu (2012) [24], the participants gained satisfaction from the environment of online learning and showed significant appreciation of a chance of working with their friends collaboratively. In addition, they believed that they could get deep insights into the content thanks to collaborative learning.

Then, in terms of teaching writing skills, online collaborative learning is a tool and tactic for brainstorming. Each member has to manipulate information, generate artifacts, and post their notes on the same platform such as Google doc or Google slide in group or pair work. This will give students the opportunity to share ideas, and at the same time, stimulate individuals as it clearly shows who joins the discussion.

Moving on to the disadvantages of online collaborative learning, the most notable one some technological restrictions such as equipment and transmission lines (Zhu, 2012) [24]. There is also concern whether students will be reluctant or cooperative with this learning method (Chiong \& Jovanovic, 2012) [6]. Additionally, the teachers are likely to have more workload to motivate students to participate and prepare lessons before classes. In particular, teachers may face issues as students do not do homework in advance. In some other cases, students may spend time sitting in front of the screen without interacting with people. Although some constraints exist, online collaborative learning is still considered an advanced method that can effectively teach writing skills, improve students' achievement, and motivate them to be active in learning.

\subsection{Previous studies on collaborative writing}

Shehadeh (2011) [1] conducted a mixed-method study to investigate the effect of collaborative writing on the quality of students' writing as well as their perceptions of collaborative writing after being exposed to this technique. There were 38 female freshmen engaged in the research. The participants shared the same background: Arabic as their first language, having studied English as a foreign language for six years, at low-intermediate proficiency level, and they were familiar with traditional methods and individual work. The students were divided into two groups: 20 students in the control group and 18 students in the experimental group. In order to measure the effectiveness of collaborative writing, the pre-test and post-test were carried out. Students were also asked to complete a questionnaire with broad and open-ended questions after the post-test to investigate their perceptions of the new experience. Students' writing was rated based on a valid writing scale including five categories: content, organization, vocabulary, mechanics, and grammar. The study concluded that, in general, collaborative writing created a profound effect on enhancing students' ability in writing in English. However, in different areas, the effect varied to different extents. Specifically, the impact was considerable in the fields of content, organization, and vocabulary, but it was negligible in mechanics and grammar. Regarding students' viewpoints towards collaborative writing, most of the experimental group students found it advantageous. Although this technique was new to them, after the treatment, they could realize the benefits it offered; in addition, they enjoyed and became more actively involved in classroom activities. Collaborative writing activities provided students with opportunities to brainstorm ideas, discuss, plan, create, and edit their writing collaboratively. Besides reinforcing students' writing skills, collaborative writing also boosted their self-confidence and speaking skills. Also, changing partners continuously during the course improved the classroom's social atmosphere.

Another quantitative research was carried out by Aminloo (2013) [2] to study the effectiveness of group work and collaborative writing on elementary-level English as a Foreign Language (EFL) learners' writing competence. Sixty-four EFL learners of different majors from the University of Tehran participated in this study. Thirty-one students were put in the treatment group, and the other 33 students were assigned to the control group. During the procedure, the instructions and most activities were the same for both the treatment and control groups, except for the writing activity. The treatment group was asked to write collaboratively while the control group worked individually. The pre-test and post-test were administered to evaluate students' performance. After the 12-session course, the students in both treatment and control groups showed significant 
improvement; however, the treatment group remarkably outperformed the control group. This result proved the effectiveness of collaborative writing. When writing collaboratively, the treatment group students could have better topic development and produce longer paragraphs with more complex sentences. Furthermore, their writing samples had better accuracy due to peer feedback, peer correction, collaboration in revising and editing.

Pham (2016) [16] examined the effectiveness of collaborative writing on individuals' writing skills and writing fluency. The action research was conducted at Ho Chi Minh City Open University with the participation of 62 sophomores of the Faculty of Foreign Languages. The controlled group consisted of 27 students, and 35 were in the experimental group. The students were asked to compose an argumentative essay. The controlled group worked individually; meanwhile, the experimental group wrote collaboratively. The author of the research used the pre-test and post-test to measure collaborative writing efficiency. The results suggested that collaborative writing produced positive effects on individuals' writing samples' quality.

\subsection{Research gaps}

In general, the above studies demonstrate the effects of collaborative writing in second language teaching and learning. Precisely, it is suggested that collaborative writing plays a pivotal role in reinforcing students' writing skills and hence improving their performance. Although these studies provide a very clear confirmation of collaborative writing effectiveness, there are still some issues that need to be clarified in future studies. The remarkable problem is that though there is a lot of research about this method, very few of them were conducted in the context of Vietnamese EFL classrooms. Each of the studies mentioned in the literature review of this research was conducted in a specific country or some parts of a country; thus, the findings should not be applied to bigger contexts, such as the context of a whole continent. When searching for research that investigates topics related to collaborative writing in Vietnamese education, only a few relevant studies could be found. Another issue is that most studies focus on the effects of offline collaborative writing, not online collaborative writing. However, with the development of Information and Communication Technology (ICT), it is necessary to integrate this method and online tools. We strongly believe that collaborative writing can bring many different effects when conducting on an online platform. These reasons urge us to conduct a study in a specific context of SIU to evaluate the effects of online collaborative writing when applying to our own students.

\subsection{Application of an online collaborative writing platform in EFL classrooms}

In previous studies, Google Documents is utilized as the main online collaborative tool for facilitating students' writing skills. Developed by Google, Google Documents is a free web-based word processor that allows multiple users to simultaneously edit the same document (Thompson, 2008) [20]. Among the four options provided by Google, including Documents, Spreadsheets, Presentations, and Drawing, Google Documents becomes the focus of this study since it seems to be the most effective platform for collaborative learning, especially writing. Google Documents offer features that are similar to Microsoft Office Word - a popular and familiar word processor to many teachers and learners. The only difference is that it allows different writers to create, view, and edit a document virtually regardless of the time and place. In other words, when a student is composing a text on Google Documents, other students can see what is being typed, make changes on their peer's drafts, or view changes made by others. What is more, if they fail to finish writing within class hours, they can save, store it online and continue to edit it at home (Yang, 2010) [22].

Recent studies have shown a myriad of outstanding effects of Google Documents on English teaching and learning. In Jeong's (2016) study [11], Google Documents was used to enhance college students' academic writing skills and motivation. The results showed positive influences on students' learning motivation, teacher-student, and student-student communication, peer-editing experience, and mutual collaboration. In terms of linguistic development, writing collaboratively on Google Documents is likely to result in more accurate grammatical production, as shown in a writing class for academic purposes of Kessler, Bikowski, and Boggs' (2012) study [12]. Besides, EFL learners, especially the young generation, also expressed great interest in applying a $2.0 \mathrm{web}$-based technology into English learning thanks to its convenience and real-time interaction (Jeong, 2016 [11]; Brodahl, Hadjerrouit, \& Hansen, 2011 [4]).

\section{METHODOLOGY}

\subsection{Research site and participants}

The research was carried out at The Saigon International University, located in District 2, Ho Chi Minh City, Vietnam. According to the school's program, English is taught in separate skills such as reading, listening, writing, and speaking; and all students will take English courses throughout six semesters with different textbooks depending on their majors. Particularly, the English-majored ones use the textbook "Q-Skills for success" (2nd edition).

The participants were 19 sophomores at the ages of 20 and 22, including 12 females and seven males. They were English majors taking part in an English writing course which lasted for 15 weeks (4 periods per week). The textbook used was "Q-Skills for Success - Reading and Writing" ( $2^{\text {nd }}$ edition). Those students were selected to participate in the research due to the following reasons. Firstly, they had a high level of competence in 
English; hence, they were likely to be confident in performing collaborative writing. Secondly, they had been learning together for more than a year and known each other well, making them feel comfortable working together. Finally, as they were required to write a thesis in English before graduation, improving their writing skills would benefit them the most.

\subsection{Research Design}

A case study was chosen as the research design for this research because it is believed that case studies allow researchers to examine the data in a specific place of investigation closely. In addition, a case study is expected to enable researchers to investigate a small number of participants (Zainal, 2007) [23]. This kind of research approach was considered appropriate for the current study because the participants were only 19 students in a particular class.

\subsection{Data collection}

According to the syllabus, there were six units of the "Q-Skills for Success - Reading and Writing" to be covered in this Writing course. Online collaborative writing was only applied when students practiced various writing genres. In particular, students were given chances to practice collaborative writing every two weeks. The entire data collection procedure is shown in table 3.1:

Table 3.1. The procedure of data collection

\begin{tabular}{|c|l|}
\hline Week & Activity \\
\hline Week 1 & $\begin{array}{l}\text { Introduction } \\
\text { Pre-test (individual) }\end{array}$ \\
\hline $\begin{array}{l}\text { Week 2, 6, 10, } \\
12,14\end{array}$ & $\begin{array}{l}\text { Applying online collaborative } \\
\text { writing (pair-work) }\end{array}$ \\
\hline Week 15 & $\begin{array}{l}\text { Post-test (individual) } \\
\text { Questionnaire }\end{array}$ \\
\hline
\end{tabular}

Methods for data collection include a pre-test, posttest, and questionnaire. In week 1 , before assigning online collaborative writing tasks to the students, the lecturer spent the first week giving a brief introduction of the course as well as Google Documents as the main tool to be used in writing activities. At the same time, the students took the pre-test individually so that the lecturer could assess their current writing ability. The test was developed as a writing test that requires the students to compose a short paragraph (around 120 words). The lecturer then collected and scored their written works. Furthermore, the students would be instructed on how to use Google Documents to serve the purpose of the course.
From week 2 to week 14, the students started using Google Documents in pairs to perform in-class writing tasks every two weeks. These proposed stages below explain how English lecturers can make good use of Google Documents in an English writing course:

Stage 1: training on how to use Google Documents in writing

The students are trained on how to use Google Documents within their groups. A student creates a Google Documents link and shares it with their group members as well as the lecturer in an Editor mode. All group members then get access to the same file and work together like working on a paper sheet. The lecturer also advises students on the differences in sharing modes: Sharing with emails enables each group member to see what other members are working on while sharing with a link. Therefore, sharing via email is recommended so that the lecturer can evaluate each student's contributions to the group work later. Each group member's contribution to the essay is presented in different colors, making it convenient for the lecturer to grade.

\section{Stage 2: training on group brainstorming}

The lecturer instructs the students to work on an outline of a writing topic. The lecturer uses the break room function to divide the class into small groups and instruct students to brainstorm the outline for the topic. The lecturer should ask the groups to delegate group leaders who will moderate each group member's tasks, and the group leaders should be the ones creating the Google Documents to share with the group members and the lecturer in mail sharing. As a member of the groups, the lecturer can support the groups, give comments or feedback, or provide the groups with necessary resources. In this stage, if the problems with mail sharing arise, the lecturer can train the students on how to work with Google Documents again so that they will not have any problems in their collaborative writing later.

\section{Stage 3: training on collaborative writing}

Once the students are used to using Google Documents within their groups, the lecturer can have them collaborate their writing as follows:

Divide the class into small groups of 4-5 students, assign the students in each group duties, and ask them to collaborate to complete a product. For example, each group has five students: one is assigned to write the introduction paragraph based on the controlling ideas in the thesis statement; three other students write three body paragraphs, and the last student is asked to write the concluding paragraph. Then, the student who has better writing skills in the group is assigned to provide peer feedback and revise the whole product.

During the writing process, every group member can use the comment box to communicate with each other and edit their essay; the lecturer herself can also support the group using this function. The lecturer also instructs 
the students on the use of the 'Explore' function, which operates as a search engine like Google Search, to provide them with necessary resources that enhance students' knowledge skills. The lecturer only gives comments in the comment box, not editing directly on students' essays.

In addition to using Google Documents for most inclass activities and homework, Google Classroom - a virtual classroom for lecturers to post/share lessons and for students to turn in their assignments - should be integrated into this activity. The lecturer shows students how a writing piece on Google Documents could be uploaded onto Google classroom by inserting its link into the submitting section.

After the students finish their task on Google Documents, the lecturer creates an assignment section on Google Classroom and asks the students to submit their work. Each pair/group copies their document's link and pastes it in the designated section on Google Classroom. After that, the lecturer can gather all students' works at once. However, suppose she wants to view, comment, or edit any documents. In that case, the pair/group composing that document has to add the lecturer's email address in the "Share" box of Google Documents with a relevant role. Suppose there is a projector in the classroom. In that case, the lecturer will show her corrections or comments of a particular writing piece to the whole class, and all students can learn from them, making learning more fun, interactive and productive.

The same procedures will be implemented when the lecturer assigns homework. Again, the students work in pairs/groups on Google Documents, share the editing permission with the lecturer and insert the link in Google Classroom's assignment section. The lecturer then checks and scores students' essays at any time at her convenience.

Peer-assessment can also be applied in the procedure. The lecturer may ask all the pairs/groups to exchange their works and give comments to other pairs/groups to learn from each other's useful ideas and mistakes/errors. The lecturer gives regular comments/feedback after students submit their work on Google Classroom. After that, students have to read and correct their mistakes based on the lecturer's comments.

Week 15: After the students finished seven collaborative tasks in total, they were required to take a post-test individually. The test took the same form as the pre-test. Scores from pre-test and post-test were marked by the lecturer and compared to measure the writing skills' development in terms of task achievement, coherence and cohesion, lexical choices, and grammatical range. After that, an online survey was sent to their individual email, and students were told to complete it within week 15 .

\subsection{Data analysis}

This study's data were collected from students' writings in their pre-test and post-tests and analyzed quantitatively. As this study adopted the case study research approach, a mixed-method design in which data from the questionnaire were analyzed qualitatively was used. The researcher scored the students' written works based on a writing rubric, which includes four categories: task achievement, coherence and cohesion, lexical choices, and grammatical range. The scoring rubric was adopted from the IELTS test's writing rubric. The scores from the pre-test and post-test of each student were then compared to examine whether the participants made any improvements in the overall quality of the text as well as the use of vocabulary and grammar. The questionnaire data were analyzed based on content analysis to categorize into different themes regarding students' perceptions towards such a learning technique. Findings drawn upon the data analysis process would be helpful to assess the impact of Google Documents on the participants' writing skills.

\section{FINDINGS}

\subsection{Students' writing quality showed in test results}

By using paired sample t-test to compare the results of pre-test and post-test, it was found that the mean scores of 19 students in their post-test were relatively higher than in pre-test. This showed that there was a difference in the scores between the two tests when online collaborative writing was integrated into the English writing course. The pre-test and post-test scores by learning collaborative writing virtually of 19 sophomores have statistical significance. This result showed that there was a very small probability of these results occurring by chance. Therefore, there was strong evidence that the teaching intervention has improved marks (by approximately 2 points). These findings revealed that learners significantly developed their writing abilities through collaborative writing.

Moreover, in terms of each test's quality, there was a difference when the students showed significant development in writing fluency and accuracy. Particularly, post-test scores in each category (task fulfillment, organization, vocabulary, and grammar) of the grading rubric increased remarkably as the students successfully fulfilled the task requirements, organized the text logically, used a wider range of vocabulary, and produced fewer grammatical errors. This could result from the collaborative work when the students helped each other within their pairs/groups to achieve the target goals. Moreover, the teaching intervention allowed the students to correct their mistakes first (by using the Grammar-check feature of Google Documents), correct their peers' mistakes, and finally correct the whole group's mistakes by referring to the lecturer's comment(s). 


\subsection{Students' progress in idea development for the essay}

Thanks to the lecturer's prompt feedback on Google Documents, students could correct their mistakes themselves and learn from each other. It was found that students stopped complaining that their mind was empty whenever they were assigned to prepare an outline for an essay. They automatically worked together in a team to build up the ideas and did the brainstorming for the essay. To do that, students did a lot of reading without being asked as before.

\subsection{Students' awareness and responsibility}

The questionnaire was synthesized by Google Forms' built-in statistical function as it counted and calculated the participants' responses into a percentage. The results revealed a high satisfaction among the students in terms of writing collaboratively in the writing course as more than half of the participants said this activity was useful for their writing skills. Although approximately onethird of the participants were not very familiar with this activity, $60 \%$ of the participants concurred that their writing skills improved after the course. In particular, online collaborative writing helped them to share ideas, organize ideas, and receive feedback from their peers. Especially when their minds were empty due to uncommon writing topics, this group-work activity effectively helped them do brainstorm together to build more vocabulary and grammar structures. Surprisingly, the majority of participants claimed that they did not encounter any difficulties when joining this activity, and they could solve their difficulties (if any) by themselves. Regarding peer-correcting, the participants made good use of the Explore and chatting functions of Google Documents and the lecturer's comments. Overall, most students believed online collaborative writing should be used to brainstorm ideas, vocabulary, and grammar structures. This positive result indicated that Google Documents could be an effective learning tool for students to learn and enhance writing skills.

\section{DISCUSSION}

The fact that there was a significant difference between pre-test and post-test scores of students' writings was in line with the prior literature of Aminloo (2013) [2], Shehade (2011) [17], and Storch (2005) [18] as they concluded that the writing ability of each individual developed after learning to write collaboratively with each other. However, a study by Kim's (2008) [13] showed a different result when there was no improvement in the quality of students' written texts regardless of group-work or individual work. Therefore, although further research should be conducted to gain an in-depth conclusion of the impact of online collaborative writing tools, Google Documents still showed its usefulness, to some extent, in enhancing EFL students' writing abilities and encouraging teamwork spirit in the 4.0 technology era. Additionally, in accordance with the previous research of Dobao and
Blum (2013) [9] regarding EFL learners' perceptions on collaborative writing, the participants' reactions towards this learning method in this study was overall positive as it brought more opportunities for active participation in terms of sharing ideas and knowledge.

As an online word-processor program, it is suggested that Google Documents should be utilized in English writing courses, which require a lot of practice in producing sentences, paragraphs, or essays with accurate grammar and structures. In traditional writing classes, students compose a written text by themselves individually, and the instructor is the one who reads, identifies errors, and marks their works. In such a case, students learn from the instructor only. On the other hand, with the involvement of Google Documents now, a group of students write and discuss together and make comments and suggestions to their peers and the lecturer to enhance the quality of their writing works before submitting their final products. In contrast to the traditional writing practice, this is expected to be beneficial to every participant taking part in the process since they can broaden their horizon by learning from their peers and teachers. Additionally, writing on an online platform is also environmentally-friendly and less time-consuming, not to mention its automatic spelling and grammar check features. Students would become more engaging and confident in all writing tasks by receiving assistance from their peers and teacher.

Last but not least, through online collaborative writing, students will express their opinions, listen to the views of others in the group, discuss different ideas, and give optimal solutions to the assigned task. Through that way of learning, students' knowledge will be less subjective and superficial. Students will be trained to develop scientific objectivity and critical thinking. In such a way of team-work that emphasizes individuals' role, the team members share their thoughts, concerns, experience, and insights to construct knowledge. Students would be excited to have each person's contribution to the class's overall success.

\section{CONCLUSION}

This case study has resulted in the improvement in students' writing abilities and team-work skills. After applying this method in teaching, the Vietnamese learners have shown improvement in different aspects, such as using proper lexical choices and making use of a wider grammatical range. The students also become more familiar with incorporating technology in studying to help them learn more actively. Last but not least, this method offers students the ability to get used to working productively with people of different backgrounds, which can develop their team-work skills afterward. After all, Google Documents has shown its effectiveness in boosting collaborative writing in many learning contexts, and it would be favorable as an effective writing tool among Vietnamese students in the college and university contexts. 
Since this research was a small-scale study, it is vital to conduct more research on this topic with a wider sample and participants from different majors and language proficiencies to generate deeper insights into this innovative teaching method. In addition, interviews should be added as one of the instruments in future research so that the data could be triangulated to increase the validity and reliability of such a study, and the students' perceptions could be explored in more detail towards the teaching method.

\section{AUTHORS' CONTRIBUTIONS}

N. T. K. C. - Designed experiments, supervised the research, and co-wrote the paper.

T. T. A. T. - Performed experiments, analysed data, and co-wrote the paper.

N. L. T. and L. T. N. T. - Designed experiments, and cowrote the paper.

\section{REFERENCES}

[1] M. Abdel Hakim, Attitudes towards collaborative writing among English majors in Hebron University, Arab World English Journal. 2(4) (2011) 136-170.

[2] M. Aminloo, Effects of collaborative writing on EFL learners writing ability at elementary level, Journal of Language Teaching and Research. 4(4) (2013) 801-806.

[3] M. Bower, D. Richards, Collaborative Learning: Some Possibilities and Limitations for Students and Teachers, Retrieved from http://web.science.mq.edu.au/ richards/papers/asc 06-collab.pdf. (2006).

[4] C. Brodahl, S. Hadjerrouit, N. K. Hansen, Collaborative writing with Web 2.0 technologies: education students' perceptions, Retrieved from https://dictionary.cambridge.org/dictionary/englis h/case-study. (2011).

[5] J. S. Bruner, Toward a theory of instruction, The Bulletin of the National Association of Secondary School Principals. 50(309) (1966) 304-312.

[6] R. Chiong, J. Jovanovic, Collaborative Learning in Online Study Groups: An Evolutionary Game Theory Perspective, Journal of Information Technology Education. 11 (2012) 81-101.

[7] Colorado State University, Case studies, Retrieved from https://writing.colostate.edu/guides/guide.cfm?gui deid=60.(1993-2020).

[8] S. E. Cooperstein, E. Kocevar-Weidinger, Beyond active learning: a constructivist approach to learning, Reference Services Review. 32(2) (2004) 141-148.
[9] A. F. Dobao, A. Blum, Collaborative writing in pairs and small groups: Learners' attitudes and perceptions, System. 41(2) (2013) 365-378.

[10] R. M. Felder, R. Brent, Cooperative Learning, Washington DC: American Chemical Society Publications. (2007).

[11] K. O. Jeong, A study on the integration of Google Docs as a web-based collaborative learning platform in EFL writing instruction, Indian Journal of Science and Technology. 9(39) (2016) 1-7.

[12] G. Kessler, D. Bikowski, J. Boggs, Collaborative writing among second language learners in academic web-based projects, Language Learning \& Technology. 16(1) (2012) 91-109.

[13] T. Kim, Korean L2 writers' previous writing experience: L1 literacy development in school, University of Hawaii Second Language Studies Paper. 27(1) (2008).

[14] S. M. Loyens, D. Gijbels, Understanding the effects of constructivist learning environments: Introducing a multi-directional approach, Instructional science. 36(5-6) (2008) 351-357.

[15] J. C. Mitchell, 'Case and situation analysis', The Sociological Review. 31 (1983) 187-211.

[16] V. P. H. Pham, The effects of collaborative writing on individual writing, Saigon University: Journal of Science. 14(39) (2016) 67-82.

[17] A. Shehadeh, Effects and student perceptions of collaborative writing in L2, Journal of Second Language Writing. 20 (2011) 286-305.

[18] N. Storch, Collaborative writing: Product, process and students' reflections, Journal of Second Language Writing. 14 (2005) 153-173.

[19] N. Storch, Collaborative writing as a site for L2 learning in face-to-face and online modes, Teaching across writing contexts and tasks. (2012) 113-129.

[20] J. Thompson, Don't be afraid to explore Web 2.0, Education digest. 74(4) (2008) 19-22.

[21] L. Vygotsky, Interaction between learning and development, Readings on the development of children. 23(3) (1978) 34-41.

[22] C. C. Yang, Using Google Docs to Facilitate Collaborative Writing in an English Language Classroom Practice, The electronic Journal for English as a Second Language. 14(3) (2010).

[23] Z. Zainal, Case study as a research method, Journal Kemanusiaan. 9 (2007) 1-6.

[24] C. Zhu, Student Satisfaction, Performance, and Knowledge Construction in Online Collaborative Learning, Educational Technology \& Society. 15(1) (2012) 127-136. 